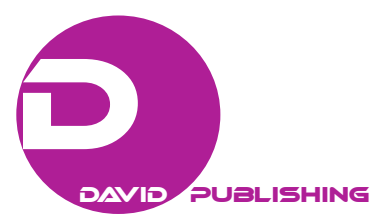

\title{
European Countries Socio-Economic Development in the Context of Europe 2020 Strategy
}

\author{
Maria Klonowska-Matynia \\ Koszalin University of Technology, Koszalin, Poland
}

This article discusses important and current issues of EU countries socio-economic development in the context of the "Europe 2020 Strategy" (a strategy for smart, sustainable, and inclusive growth). The main objective of this article is to prepare hierarchy and classification of the EU countries, showing the degree of core indicators implemented as described in the framework of the "Europe 2020 Strategy". The author attempts to isolate groups of the EU countries which present similar development levels on the basis of accepted development indicators. It attempts to determine: (1) the level of socio-economic development EU countries (based on synthetic indicator); (2) trends in changing of socio-economic development level EU countries; and (3) the main factors determining the level of socio-economic development level EU countries. Based on estimated indicators, the following assumptions were verified: The development distance among EU countries has steadily decreased and the economical factors are the most strongly determining factors of sustainable development. Selected methods of multivariable objects hierarchy and classification have been used in the study. In order to measure the level of socio-economic development of the EU countries, linear ordering has been applied, based on the standardized sums method. As a result, a relative level indicator of development has been assigned to each country. The classification of the EU countries has been made mainly according to the Ward hierarchical agglomeration procedure. Thus, groups of countries appeared have been similar in terms of analyzed characteristics. It allowed an attempt to determine basic features of these countries' groups in terms of factors determining their development. Analysis will be carried out in spatial and time dimension as a part of the research. The subject of spatial analysis will be the EU countries (including Norway and Croatia), in particular their socio-economic development indicators as described in the "Europe 2020 Strategy" framework. The time range of the study includes 2004 and 2014. Eurostat has been the main data source. Based on three pillars (social, economic, and environmental), it is concluded that the development gap among European countries has reduced, though the average level of development is slightly increasing in Europe. The catching-up process of development by the countries of Central and Eastern Europe, among which the leader is Poland, can be visibly observed. It turned out that as many as three of the five traits under examination (two of them economic pillars and one of the society pillars) are comparatively strong, this explains the value of the development index, as the environmental and educational component has proven to be of less significance.

Keywords: socio-economic development, Europe 2020 Strategy, hierarchy, classification, European countries, Ward procedure

Maria Klonowska-Matynia, Ph.D., Koszalin University of Technology, Koszalin, Poland.

Correspondence concerning this article should be addressed to Maria Klonowska-Matynia, Ul. Kwiatkowskiego 6E, Koszalin 75-343, Poland. E-mail: maria.klonowska-matynia@tu.koszalin.pl. 


\section{Introduction}

EU member states, over the years, have been trying to transform the EU economy into the most competitive knowledge-based economy in the world (Foray \& Lundvall, 1996; Rodrigues, 2003; 2004; Stiglitz, 1999). The problem of defining a diverse knowledge-based economy has resulted in many papers which lead to the conclusion that it is extremely difficult to identify one universal definition (Klonowska-Matynia, 2013). Commonly used terms are: the new economy, the digital economy, the network management economy (also called the network economy) (Coyle \& Quah, 2002), and the learning economy (Foray \& Lundvall, 1996). The terms "knowledge-driven economy" stated by Stiglitz (1999), "the post-industrial economy" introduced by Bell (1973), and the "third wave" created by Toffler (1997), determine the service economy and tertiary civilization, which emphasize the dominance of a third sector in production and employment. The process of implementing reforms, using any combination of knowledge in Europe, was launched back in the 80's through the implementation of the Lisbon strategy. Currently, the general priorities of building a knowledge-based economy are continuing based on the post-Lisbon agenda-the "Europe 2020 Strategy" (Klonowska-Matynia, 2013). It is emphasized that further socio-economic development of European countries (but not only) may be obtained by future generations only if coherence among the three components of development, i.e., environment, society, and economy, is maintained (Jones \& Schneider, 2006).

Seeking modern drivers of economic growth, Europe currently uses the concept of development, allowing it to unlock its development potential. Key factors of socio-economic development in this economic model are factors associated with the resource of knowledge, among which are included, investment in innovation and high technology, human capital, and economic cooperation between scientific and research centres (Bercovitz \& Feldman, 2006; Anselin, Varga, \& Acs, 1997; Antonelli, 1999; Nonaka \& Takeuchi, 1995; Klonowska-Matynia, 2012). However, of all of these factors, modern scholars attribute the dominant role of human capital (Becker, 1964; Schultz, 1980; Mincer, 1962). The relationship between human capital and economic growth, among others, is described by researchers who have positively verified that an increase in the average IQ of a nation by one percentage point is associated with a permanent annual growth of $0.11 \%$ in GDP per capita (Romer, 1986; 1990; Lucas, 1988; Jones \& Manuelli, 1990; Jones \& Schneider, 2006). Mankiw, Romer, and Weil (1992) confirmed that the main reason for developmental differences in achievement by individual countries GDP is technology, but there is potential for countries that have "social potential" and manage to mobilize resources, such as investment, education and research, and development to catch up (Fageberg, 1994). In addition to smart growth, based on knowledge and innovation and of actions conducive to inclusive growth, this model promotes sustainable growth. This involves a movement towards a low carbon economy. This means an efficient use of natural resources, the promotion of energy efficiency, and the use of renewable sources of energy (European Commission, 2010).

Securing economic growth and employment in Europe currently requires to increase the efficiency of the resources used. It is a condition of achieving progress in addressing climate change and reducing greenhouse gas emissions in the EU by $80 \%-95 \%$ by 2050 . It is also necessary for the protection of valuable ecological resources, the functions that they perform, and the quality of life of both current, as well as future generations of people (European Commission, 2011). These priorities formed the basis for development undertaken in this article on the typology and classification of European countries on the basis of their synthetic index of socio-economic development. This is estimated on the basis of selected features describing changes in the areas 
of environment, economy, and society, pillars of the reform program of the "Europe 2020 Strategy" (European Commission, 2011; Giovannini \& Linster, 2005). This article attempts to obtain an answer to the question about the direction of changes in the level of development taking place over the years from 2004 to 2014 in European countries, as well as identifying factors which determined the levels of development achieved. In order to write this article, a decreasing gap in development among EU countries was assumed and at the same time the continuing disparities between the core countries and the periphery (countries that joined the EU after 2004). In addition, it assumes the key role of economic factors as a strong determining factor in the level of the estimated rate of socio-economic development.

\section{Method and Scope of Data}

International research uses various indicators and measurements to measure and evaluate the differences in the socio-economic development of countries. The most popular, though imperfect in its design, is GDP and HDI is also used to assess development. This article is an attempt to create a synthetic index, based on the characteristics of those currently selected by the European Commission to assess the sustainable development of the EU countries included in the Europe 2020 program. The strategy takes into account three pillars in its design: economy, society, and a factor often overlooked in other comparative analyses, namely the environmental factor. In order to determine the level of development achieved by the EU in the framework of the "Europe 2020 Strategy", , a linear ordering method based on the sum of standardized values was used. As a result of this, each of the countries is assigned a relative indicator describing to what extent the European strategy has been implemented. It involves adding up the value of standardized pre-included features, among which are negative stimulants, which are taken into account by multiplying the value by -1 . A synthetic variable describing the overall level of sophistication of countries in implementing the "Europe 2020 Strategy" can be calculated by using the following formula (Nowak, 1990):

$$
W_{i}=\frac{\sum_{j=1}^{k} z_{i j}}{\sum_{j=1}^{k} \max \left\{z_{i j}\right\}}
$$

description:

$$
z_{i j}=x_{i j}+\left|\underset{i}{\min }\left\{x_{i j}\right\}\right|
$$

and $x_{i j} j$ are the value characteristics of the country number $i$.

This gives an indicator of the level of development. It results in a value between 0 and 1 , the bigger the value, the better it is in terms of the general criteria. The classification of countries was based on Ward's hierarchical agglomeration procedure described by the following scheme (Nowak, 1990):

(1) Each object is treated as a separate entity;

(2) The distance matrix is searched for the minimum distance;

(3) The closest objects are combined in one group of two elements;

\footnotetext{
1 The study involved 29 European countries and the choice of countries for analysis was conditioned by data availability. Among accepted for testing 29 European countries, Norway is not an EU member. Croatia has been a member of the EU on January 1, 2014.
} 
(4) The distance between the newly created group and all other groups is determined;

(5) Steps 2-5 are repeated until all the objects form one group.

In Ward's method, one of the variants of hierarchical clustering, the distance between groups of objects, is determined by the following formula (Nowak, 1990):

$$
\begin{gathered}
d_{i r}=\frac{N_{i}+N_{p}}{N_{i}+N_{r}} d_{i p}+\frac{N_{i}+N_{q}}{N_{i}+N_{r}} d_{i q}-\frac{N_{i}}{N_{i}+N_{r}} d_{p q} \\
d_{p q}=\min _{i, j}\left\{d_{i j}\right\}
\end{gathered}
$$

where $d_{i j}$ is Euclidean distance between classified objects; $d_{i p}$ is the distance between one of the two groups joined on the stage of the procedure, that contains example elements and other groups (not to be joined at that stage), the number of which is $N i ; d_{i q}$ is the distance between the other groups combined on the stage of the counting $N q$ elements $N i$ and other groups; and $N r$ is the number of elements in the newly formed group.

To estimate the development of a synthetic indicator of the Europe 2020, the annual data reported for these areas, obtained from Eurostat, were adopted. The main objectives for this strategy are defined as:

- X1 employment - the employment rate of people aged 20-64 as a \%;

- X2 sphere of research and development - an indicator of the size of spending on R\&D described as a \% of GDP;

- X3 education - an indicator described as the share of persons aged 18-24 who are early school leavers as a $\%$

- X4 poverty and social exclusion — an indicator of the proportion of people at risk of poverty or social exclusion as a \%;

- $\mathrm{X} 5 \mathrm{CO}_{2}$ emissions - the share of energy from renewable sources in gross final energy consumption as a \%.

The time component of the study included two points in time 2004 and 2014 shown in Table 1.

Table 1

\begin{tabular}{|c|c|c|c|c|c|c|c|c|c|c|}
\hline \multirow{3}{*}{ Country } & \multirow{2}{*}{\multicolumn{2}{|c|}{$\begin{array}{c}\mathrm{X} 1 \\
\text { Destimulant }\end{array}$}} & \multicolumn{2}{|r|}{$\mathrm{X} 2$} & \multicolumn{2}{|r|}{$\mathrm{X} 3$} & \multicolumn{2}{|c|}{$\mathrm{X} 4$} & \multicolumn{2}{|c|}{ X5 } \\
\hline & & & & nulant & & ulant & & mulant & & ulant \\
\hline & 2014 & 2004 & 2014 & 2004 & 2014 & 2004 & 2014 & 2004 & 2014 & 2004 \\
\hline Belgium & 67.3 & 65.6 & 2.28 & 1.86 & 9.8 & 13.1 & 20.8 & 21.6 & 7.9 & 1.9 \\
\hline Bulgaria & 65.1 & 60.1 & 0.65 & 0.49 & 12.9 & 21.4 & 48 & 61.3 & 19 & 9.2 \\
\hline Czech Republic & 73.5 & 70.1 & 1.91 & 1.2 & 5.5 & 6.3 & 14.6 & 19.6 & 12.4 & 6 \\
\hline Denmark & 75.9 & 77.6 & 3.06 & 2.48 & 7.7 & 8.8 & 18.9 & 16.5 & 27.2 & 14.9 \\
\hline Germany & 77.7 & 68.8 & 2.85 & 2.5 & 9.5 & 12.1 & 20.3 & 18.4 & 12.4 & 5.2 \\
\hline Estonia & 74.3 & 70.6 & 1.74 & 0.85 & 11.4 & 13.1 & 23.5 & 26.3 & 25.6 & 18.4 \\
\hline Ireland & 67 & 71.5 & 1.58 & 1.23 & 6.9 & 13.1 & 29.5 & 24.8 & 7.8 & 2.4 \\
\hline Greece & 53.3 & 64 & 0.8 & 0.55 & 9 & 14.7 & 35.7 & 30.9 & 15 & 7.1 \\
\hline Spain & 59.9 & 65.2 & 1.24 & 1.06 & 21.9 & 32 & 27.3 & 25 & 15.4 & 8.3 \\
\hline France & 69.8 & 69.5 & 2.23 & 2.16 & 8.5 & 12.1 & 18.1 & 19.8 & 14.2 & 9.3 \\
\hline Croatia & 59.2 & 59.6 & 0.81 & 1.05 & 2.7 & 5.4 & 29.9 & 30.7 & 18 & 15.2 \\
\hline Italy & 59.9 & 61.5 & 1.26 & 1.09 & 15 & 22.9 & 28.4 & 26.4 & 16.7 & 5.1 \\
\hline Cyprus & 67.6 & 74.9 & 0.48 & 0.37 & 6.8 & 20.6 & 27.8 & 25.3 & 8.1 & 2.7 \\
\hline
\end{tabular}

Output Characteristics Adopted for Testing (2004, 2014) 
Table 1 continued

\begin{tabular}{|c|c|c|c|c|c|c|c|c|c|c|}
\hline \multirow{3}{*}{ Country } & \multirow{2}{*}{\multicolumn{2}{|c|}{$\begin{array}{c}\mathrm{X} 1 \\
\text { Destimulant }\end{array}$}} & \multicolumn{2}{|c|}{$\mathrm{X} 2$} & \multicolumn{2}{|c|}{$\mathrm{X} 3$} & \multicolumn{2}{|c|}{$\mathrm{X} 4$} & \multicolumn{2}{|c|}{$\mathrm{X} 5$} \\
\hline & & & & nulant & & aulant & & mulant & & nulant \\
\hline & 2014 & 2004 & 2014 & 2004 & 2014 & 2004 & 2014 & 2004 & 2014 & 2004 \\
\hline Latvia & 70.7 & 69.3 & 0.6 & 0.42 & 8.5 & 14.7 & 35.1 & 46.3 & 37.1 & 32.8 \\
\hline Lithuania & 71.8 & 69 & 0.95 & 0.75 & 5.9 & 10.5 & 30.8 & 41 & 23 & 17.3 \\
\hline Luxemburg & 72.1 & 67.7 & 1.16 & 1.63 & 6.1 & 12.7 & 19 & 16.1 & 3.6 & 0.9 \\
\hline Hungary & 66.7 & 62.1 & 1.41 & 0.88 & 11.4 & 12.6 & 33.5 & 32.1 & 9.8 & 4.4 \\
\hline Malta & 66.3 & 57.9 & 0.85 & 0.51 & 20.4 & 42.1 & 24 & 20.2 & 3.8 & 0 \\
\hline Nederland & 76.1 & 74.9 & 1.98 & 1.93 & 8.6 & 14.1 & 15.9 & 16.7 & 4.5 & 1.8 \\
\hline Austria & 74.2 & 70.8 & 2.81 & 2.24 & 7 & 9.5 & 18.8 & 17.5 & 32.6 & 22.8 \\
\hline Poland & 66.5 & 57.3 & 0.87 & 0.56 & 5.4 & 5.6 & 25.8 & 45.3 & 11.3 & 7 \\
\hline Portugal & 67.6 & 72.6 & 1.36 & 0.74 & 17.4 & 39.4 & 27.5 & 27.5 & 25.7 & 19.3 \\
\hline Romania & 65.7 & 63.5 & 0.39 & 0.39 & 18.1 & 22.4 & 40.4 & 45.9 & 23.9 & 17 \\
\hline Slovenia & 67.8 & 70.4 & 2.59 & 1.39 & 4.4 & 4.3 & 20.4 & 18.5 & 21.5 & 16.1 \\
\hline Slovakia & 65.9 & 63.7 & 0.83 & 0.51 & 6.7 & 6.8 & 19.8 & 32 & 9.8 & 6.7 \\
\hline Finland & 73.1 & 72.2 & 3.31 & 3.45 & 9.5 & 10 & 16 & 17.2 & 36.8 & 29 \\
\hline Sweden & 80 & 77.4 & 3.3 & 3.58 & 6.7 & 9.2 & 16.4 & 16.9 & 52.1 & 38.7 \\
\hline United Kingdom & 76.2 & 75 & 1.63 & 1.67 & 11.8 & 12.1 & 24.8 & 24.8 & 5.1 & 1.2 \\
\hline Norway & 79.6 & 78.2 & 1.66 & 1.57 & 11.7 & 4.7 & 14.1 & 15.8 & 65.5 & 58.6 \\
\hline
\end{tabular}

The collected material allowed to try to assess and examine the relationship among the measured traits. For this purpose, the Pearson correlation coefficient was used (see Table 2). Studies have shown that there is a relatively strong positive correlation between the employment rate and spending on R\&D $(r=0.603)$. An equally strong, but negative relationship exists between the threat to welfare and unemployment $(r=-0.606)$, and $\mathrm{R} \& \mathrm{D}(r=-0.689)$. The use of non-conventional energy in the assessment of the level of development should be assessed as an important element. The environmental factor shows the highest correlation with the rate of employment $(r=0.405)$ and also demonstrates a positive relationship, but with less force occurring in relation to expenditures on R\&D. A negative interdependence was observed in correlation with the number of early school leavers and the number of people at risk of poverty. All these relationships should be assessed as correct. ${ }^{2}$ The four countries with the highest level of development at the same time have the highest share of use of non-conventional energy, with Norway having twice as much as Denmark and Austria.

Table 2

Correlations Between the Measured Trait 2014

\begin{tabular}{llllll}
\hline & Emp. & R\&D & GasEmis. & Edu. & Pov. \\
\hline Emp. & 1 & & & & \\
R\&D & 0.603341 & 1 & & & \\
GasEmis. & 0.405058 & 0.32877 & 1 & 1 & 1 \\
Edu. & -0.23358 & -0.24453 & -0.01923 & 0.299922 & 1 \\
Pov. & -0.60612 & -0.6898 & -0.17088 & & \\
\hline
\end{tabular}

In view of this interdependence determining the strength and direction between the measured traits, the current efforts by EU governments to increase spending on R\&D sector should be considered most reasonable.

\footnotetext{
2 The results show a similar correlation, but still greater interdependence in 2014 than that in 2004 .
} 
The first seven countries characterized by the highest rate of growth at the same time show the highest expenditure on R\&D. Among the countries that spend the least on science and research is Poland. Apart from our country, Lithuania, Malta, Slovakia, Croatia, Greece, Latvia, Bulgaria, Cyprus, and Romania also spend less than $1 \%$ of GDP on these goals. It is definitely still not enough to boost innovation in these economies. Currently, the countries associated with the technological advantage are spending significantly greater than the national target for 2020, for example, in South Korea in 2010, investment was equal to $3.74 \%$ of GDP, US GDP $2.88 \%$, Germany $2.82 \%$ of GDP, Finland $3.87 \%$ of GDP, and the United Kingdom $1.77 \%$ of GDP (Klonowska-Matynia \& Sasin, 2015). Currently, Sweden, Finland, and Denmark invest the most in science and innovation (approx. 3\% of GDP), as well as Austria and Slovenia (approx. 2.5\% of GDP), based on Eurostat shown in Table 3.

Table 3

Correlations Between the Measured Trait 2004

\begin{tabular}{llllll}
\hline & Emp. & R\&D & GasEmis. & Edu. & Pov. \\
\hline Emp. & 1 & & & & \\
R\&D & 0.55202 & 1 & & & \\
GasEmis. & 0.445213 & 0.29639 & 1 & & \\
Edu. & -0.25979 & -0.36209 & -0.25644 & 1 & 1 \\
Pov. & -0.55322 & -0.65488 & -0.06095 & 0.133726 & 1 \\
\hline
\end{tabular}

\section{Results of the Research}

The resulting hierarchy has enabled the countries to be grouped into five different classes, relatively homogeneous internally, in terms of the level of synthetic index of European socio-economic development for 2020. Typology results indicate that in both 2004 and 2014, they were characterized by the highest level of development of the Scandinavian countries (i.e., Sweden, Norway, and Finland) which obtained the highest index values. Bulgaria and Romania, the newest member states in the EU structure fared the worst in the evaluation, as well as Malta and the countries of Southern Europe: Spain, Greece, and Italy, who have been struggling with economic problems for several years (see Table 4).

When assessing the low position of Bulgaria and Romania in the resulting typology, it should be emphasized that despite the fact that the level of development of these economies was estimated to be similar, and de facto, the lowest levels in Europe, their situation is significantly different. First of all, Bulgaria remained in the penultimate place in the standings but has improved by almost $44 \%$ compared to 2004 . The relatively low position of this country could be determined by a factor associated with the social sphere. Bulgaria, despite a marked improvement, still recorded one of the highest rates of poverty risk in Europe (see Table 1). In addition, it is not without significance that there appears to be a low level of expenditure by the country in the field of research and development. It should be emphasized that both Bulgaria and Romania recorded the lowest rate of GDP percentages and in 2014 this share only amounted to $45 \%$ and $55 \%$ of the EU average respectively. In 2004 , it was only $34 \%$ of the EU average, which directly affects the published information for the above purpose. In comparison, the world's largest economies, e.g., the United States reached $150 \%$ of the EU average, and Norway $186 \%{ }^{3}$ In assessing the situation of Romania, there was a clear inhibition of the development process in the country. A causative agent of this situation could be, as in the case of Bulgaria, one of the lowest

\footnotetext{
${ }^{3}$ Estimated value for the $28 \mathrm{EU}$ countries are from Eurostat.
} 
expenditures on the R\&D sector in Europe and the largest risk of poverty and the accompanying failure of a high proportion of people to continue their education. Over the decade, the level of Romania's development index decreased by as much as $14 \%$ compared to 2004 , which in the case of this country, is a negative phenomenon.

A different specificity is characterized by Malta. The social and economic situation of the country does not differ significantly from other countries classified in the same group, with one exception, in 2004 and in 2014, a slight increase in the share of non-conventional energy use contributed to the relatively low score against Malta compared to other countries. In this country, there was also growth in the number of people at risk of poverty (see Table 1). Ultimately, however, Malta was among the countries with the highest human development index increment (47\%).

Interestingly, the results for Poland showed the largest increase (almost 52\%) in estimated growth rate compared to the other European countries analyzed. Certainly, the outcome of this influence was to reduce the number of people at risk of poverty by approximately $45 \%$ (it had, along with Romania and Bulgaria, one of the highest rates in 2004). There was also a significant increase in expenditure on R\&D by 55\% and employment by $16 \%$ (although they are still among the lowest in Europe). The improvement in living conditions was certainly a consequence of the dynamic development of Poland during this period. In addition, Poland can boast one of the lowest rates of early school leavers, which may be affected by compulsory schooling and free higher education. But here this paper is not able to talk about the simple relationship with the quality of teaching, which remains outside the monitoring strategy.

In looking at the situation of countries that achieved inferior results in 2014 compared to 2004, it can be concluded that the overall restless economic situation in world markets has also had an effect. Of the 29 analyzed countries, as many as 10 recorded a lower rate of socio-economic development than in 2004. Moreover, in 10 countries, there has been a decline in employment. It should, therefore, be no surprise that at the same time, in 12 countries, the number of people living in social poverty, as a direct result of loss of income has increased. This has led to a need to reduce spending on current consumption. Analyzing the dynamics of GDP also found that most countries recorded a slowdown in economic growth which continued in 2012. It is true that this was not a single incidence. The economic slowdown was felt in global markets from 2007 onwards. In 2014, it is visible that these losses resulted in a slow down in most countries, including Greece, Cyprus, Croatia, and Italy (see Figure 1).

Turning to the typology of countries affected in 2004, based on the development of the estimated synthetic index, five classes were selected: The first and second were sets of three elements with the highest and a high level of development. Dominating here are the Scandinavian countries (Sweden, Norway, and Finland) as well as Denmark, Austria, and Slovenia. The grouping actually includes similar states because of their location and standard of living, except for Slovenia, which is a relatively new member of the EU structure. Norway remains outside the EU structure. The most numerous classes - the third (nine countries) and fourth (10 countries), include countries with a medium level of development. An extreme fifth group consists of four countries characterized by the lowest level of development in the year studied, including two (Poland and Malta), who formally became members of the EU in 2004, and two more (Romania and Bulgaria) not granted membership until three years later (see Table 4). 
Table 4

Indicator of Socio-Economic Development Strategy Europe 2020. Hierarchy of Countries

\begin{tabular}{|c|c|c|c|c|c|c|c|}
\hline Lp. & 2014 & Index value & Groups $^{\mathrm{a}}$ & Lp. & 2004 & Index value & Groups \\
\hline 1 & Sweden & 0.896904 & \multirow{2}{*}{1} & 1 & Sweden & 0.88499 & \multirow{3}{*}{1} \\
\hline 2 & Norway & 0.807868 & & 2 & Norway & 0.881349 & \\
\hline 3 & Finland & 0.763394 & \multirow{6}{*}{2} & 3 & Finland & 0.789791 & \\
\hline 4 & Denmark & 0.739106 & & 4 & Denmark & 0.734996 & \multirow{3}{*}{2} \\
\hline 5 & Austria & 0.738139 & & 5 & Austria & 0.685056 & \\
\hline 6 & Germany & 0.662552 & & 6 & Slovenia & 0.629934 & \\
\hline 7 & Slovenia & 0.654557 & & 7 & Netherlands & 0.600001 & \multirow{9}{*}{3} \\
\hline 8 & Czech Republic & 0.652928 & & 8 & Germany & 0.596985 & \\
\hline 9 & Netherlands & 0.609418 & \multirow{5}{*}{3} & 9 & France & 0.59279 & \\
\hline 10 & France & 0.595367 & & 10 & Czech Republic & 0.561631 & \\
\hline 11 & Estonia & 0.578517 & & 11 & United Kingdom & 0.557664 & \\
\hline 12 & Luxembourg & 0.535435 & & 12 & Luxembourg & 0.527686 & \\
\hline 13 & Belgium & 0.526604 & & 13 & Estonia & 0.526713 & \\
\hline 14 & Lithuania & 0.51802 & \multirow{9}{*}{4} & 14 & Ireland & 0.501432 & \\
\hline 15 & United Kingdom & 0.504108 & & 15 & Belgium & 0.499912 & \\
\hline 16 & Latvia & 0.484441 & & 16 & Croatia & 0.453243 & \multirow{10}{*}{4} \\
\hline 17 & Slovakia & 0.478149 & & 17 & Lithuania & 0.45059 & \\
\hline 18 & Poland & 0.467284 & & 18 & Latvia & 0.447386 & \\
\hline 19 & Ireland & 0.461206 & & 19 & Cyprus & 0.439295 & \\
\hline 20 & Croatia & 0.433058 & & 20 & Slovakia & 0.410853 & \\
\hline 21 & Portugal & 0.41691 & & 21 & Portugal & 0.394133 & \\
\hline 22 & Cyprus & 0.415598 & & 22 & Greece & 0.379778 & \\
\hline 23 & Hungary & 0.384184 & \multirow{7}{*}{5} & 23 & Hungary & 0.378074 & \\
\hline 24 & Italy & 0.339417 & & 24 & Italy & 0.358159 & \\
\hline 25 & Malta & 0.291713 & & 25 & Spain & 0.357871 & \\
\hline 26 & Greece & 0.273963 & & 26 & Poland & 0.306499 & \multirow{4}{*}{5} \\
\hline 27 & Spain & 0.267857 & & 27 & Romania & 0.295349 & \\
\hline 28 & Bulgaria & 0.255466 & & 28 & Malta & 0.198762 & \\
\hline 29 & Romania & 0.254039 & & 29 & Bulgaria & 0.177762 & \\
\hline
\end{tabular}

Notes. ${ }^{\mathrm{a}}$ Span class 0.128573 , compartments of equal span; ${ }^{\mathrm{b}}$ Span class 0.141446 , compartments of equal span.

The typology of countries conducted for 2014 allowed to extract, as for 2004, the five groups of countries, different from each other, but relatively homogeneous (internally similar). Moreover, the groups of countries obtained are more equal in number to those of the previous period. The order of the top 10 countries actually remains very similar to 2004, with the dominant position of the Nordic countries and Western Europe. Also, similarly, as in 2004, the fourth and fifth grade European countries are dominated by the centre-east and south, which are characterized by the lowest levels of development (see Table 4).

Assessing the changes that have taken place in the level of socio-economic development in the year 2014 compared to 2004, it was observed that, in general, positive changes in the level of development took place in 19 countries (i.e., $66 \%$ of those surveyed). Less variation in the level of development of the countries surveyed in 2014 than in 2004 is also seen. The difference between the estimated indicator for the most and least developed country (Sweden and Romania) in 2014 amounted to 0.64, while in 2004 (Sweden and Bulgaria), the 
difference was 0.7. In addition, there is an apparent rise in the average level of the human development index in 2014 of approximately $2.7 \%$ compared to 2004 .

Countries, classified in the first, second, and the third group in terms of the level of development achieved (except Estonia, Slovenia, and the Czech Republic), generate a higher GDP than the EU average. There are interesting cases of standards that cannot be described by the template. Some countries: Estonia, Slovenia, and the Czech Republic, which are against the background of countries of Central and Eastern Europe, are characterized by a higher level of development, while their GDP is calculated at a level lower than the EU average $(72 \%, 83 \%$, and $80 \%$ respectively). The attempt to establish a statistically significant dependence between the resultant level of the indicator of development and the size of GDP showed that, among the measured traits, there is a positive correlation of medium intensity ( $r=0.632$ in $2014 ; r=0.49$ in 2004). So it can be accepted that the greater the GDP a country generates (here measured as a \% of the EU average for 28 countries), the higher the rate of growth is achieved (see Figure 1).

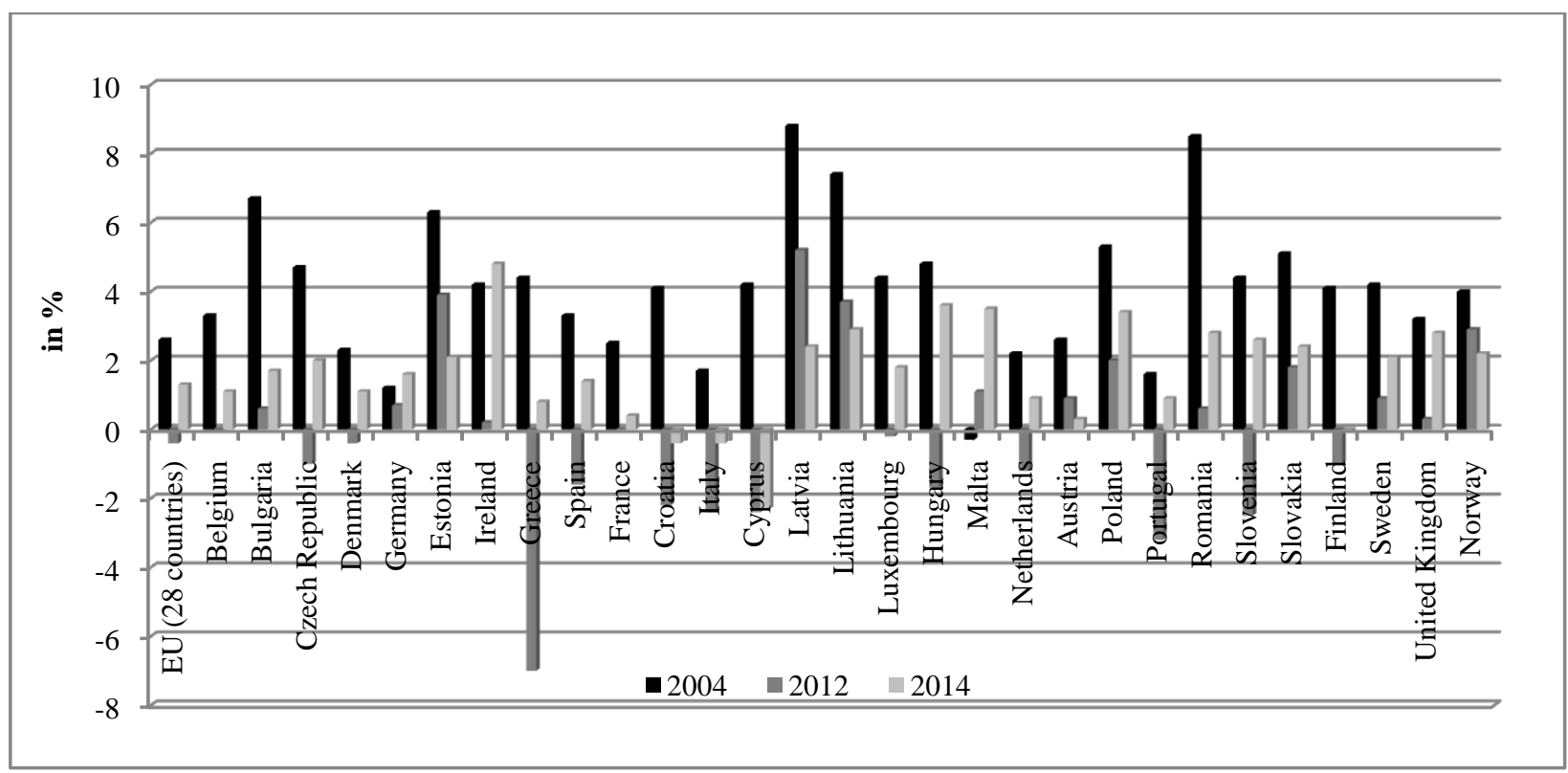

Figure 1. GDP growth rate (\%) in 2004, 2012, and 2014. Source: Own elaboration based on Eurostat.

Assessing the dynamics of changes in the level of the human development index, which occurred in 2014 in comparison with 2004, the biggest positive changes were observed in Poland, Malta, and Bulgaria. Slightly smaller, but also positive changes have taken place in Lithuania, Slovakia, and the Czech Republic (Figure 2). If this paper looks in more detail at the situation of these countries, very clear changes are observed in the evolution of the individual traits accepted for testing, and so, for example, in the case of Poland, influence on this progress was increased by the use of renewable energy (almost 61\%), employment (16\%), and a significant drop in poverty (almost 45\%). Malta recorded an improvement, mainly in the field of education, by reducing the number of early school leavers by nearly $52 \%$, changes have occurred in the labor market, where it increased employment by $15 \%$, and in the use of non-conventional energy. Bulgaria recorded a change comparable to Malta. Poverty was reduced by approximately $22 \%$ and the number of people leaving early education by almost $40 \%$. Estonia and Slovakia have invested primarily in the R\&D sector (104\% and 63\% respectively) and in the use of non-conventional energy (by 39\% and 46\%) (see Table 1). 
In 10 countries, including the highest placed in the typology, i.e., Norway and Finland, regression was observed. The most dramatic drop in the level of development was observed mainly in Greece and Spain (28\% and $25 \%$ respectively), as well as in highly developed countries in Europe, such as Ireland, Italy, and the UK. The decrease in growth rate occurred even among the newest members of the EU, i.e., Croatia, Cyprus, and Romania. There has been particularly pronounced progress in Poland, Bulgaria, and Malta. These countries have improved their efficiency in the implementation of development goals, among which Poland recorded the highest progress and development. This had positive implications in moving from the fifth to the fourth group and a clear improvement in the human development index in 2014 by almost 52\% (see Figure 2 and Table 4).

Analyzing the growth rate of development in relative terms, i.e., in relation to the average index in 2004 , a unidirectional positive rate of change of the development indicator in all countries was observed but with varying intensity. Given that the average growth rate of development in the period 2004-2014 amounted to approximately $13 \%$, the countries were classified into four groups:

- Group 1: characterised by higher than average growth rates and a higher index than the relative average level of development-United Kingdom;

- Group 2: characterised by a higher than average growth rate index but lower than the relative average level of development-13 countries;

- Group 3: characterised by a lower than average growth rate and higher than average level of relative development-11 countries;

- Group 4: characterised by a lower than average rate of increase in rate indicator and a lower than average relative level of development - four countries (Belgium, Croatia, Cyprus, and Ireland).

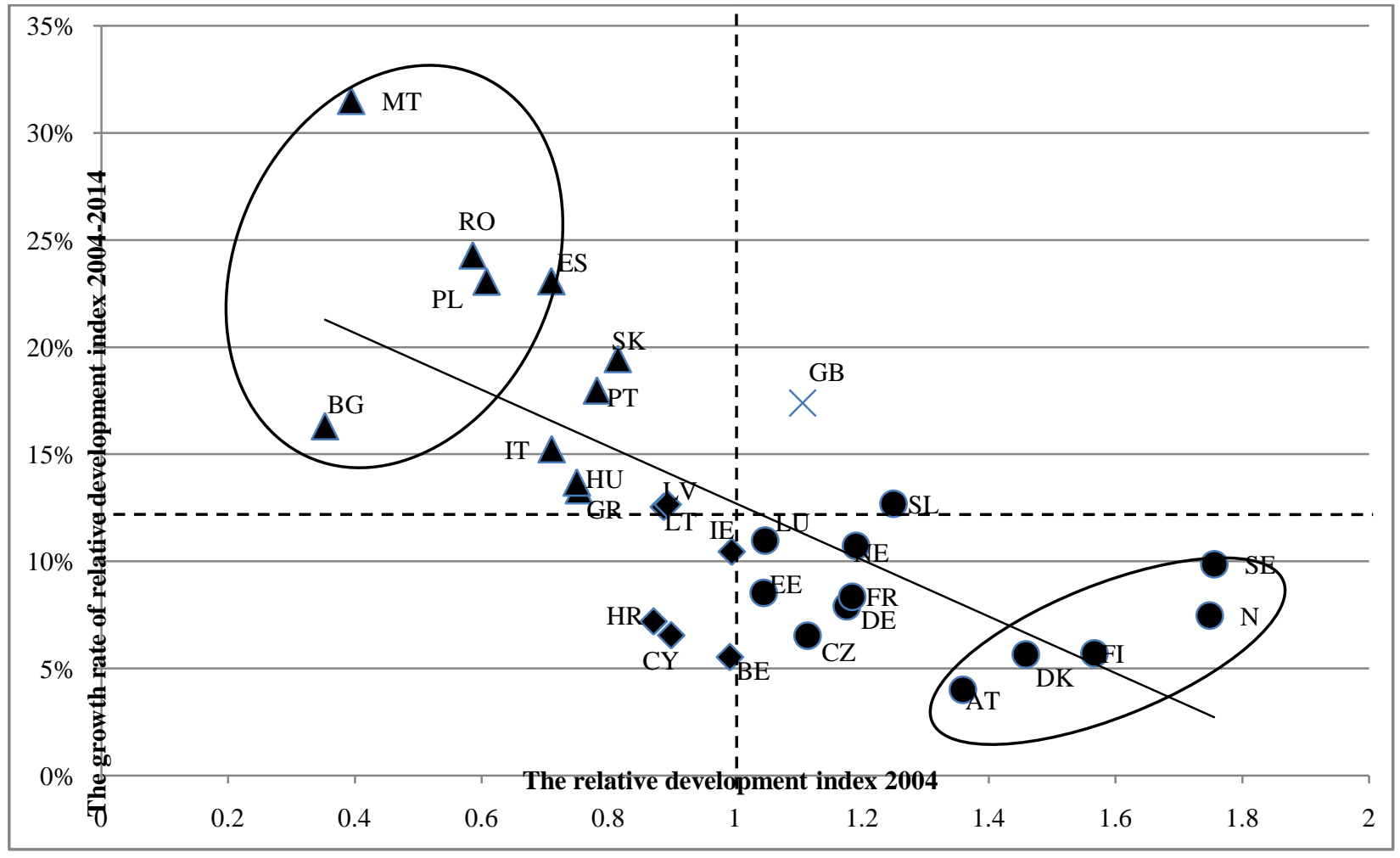

Figure 2. Changes of the relative development indicator Europe Strategy 2020. Source: Own elaboration. 
In conclusion, the so-called new (referred to as peripheral) EU countries are characterized by a still lower than average level of development than the countries of the so-called core of the EU, but the rate of change is much higher. In some countries, it is more than twice the average rate in Europe. The southern countries of Europe, i.e., Portugal, Greece, and Italy, are performing similarly but the most dominant countries are Spain with a growth rate of $23 \%$ and Malta with $32 \%$. Changes in the levels of development of countries in the so-called core countries/core EU are less dynamic, which may indicate that those countries have reached a relatively high level of development. The exception is the United Kingdom which is the only country that acquired the highest status, although the rate of growth of development at a level of $17 \%$ is not as high as it is in, for example, Malta and Poland. However, it gives rise to the recognition of these trends as very favorable. The regularity of the verified statistical test was also observed. The Pearson correlation coefficient $(r=-0.7)$ gives rise to the acceptance of the thesis about the existence of a negative relationship between the relative level of human development index and the rate of its growth.

\section{The Grouping of Countries Using Ward's Method}

The application of Ward's method in the above procedure allowed to make a grouping of countries which are similar in terms of their analyzed qualities, which enabled the determination of the basic properties of (these groups) countries in the context of the factors determining their sustainable development. The charts below illustrate the mutual absolute distances of individual countries or their sub-groups called bond distances and the relative distance as a percentage of the maximum distance. The classification of countries was made based on data for 2004, when the maximum distance of bonds amounted to 16.99 .

As a result of the application of Ward's method, several different classifications in terms of the number of groups and the degree of their homogeneity can be obtained. Of course with a larger number of clusters, there are also shorter distances within these clusters. For 2004, by cutting the "tree branches" at the level of 3.73 (22\% of maximum distance), five clusters are got, while for 2012, by cutting branches on a relatively similar level of 4.77 (24\% of maximum distance) six clusters are given (Klonowska-Matynia \& Sasin, 2015).

In the grouping carried out for 2004 on a relatively large number of nine cluster distances, the bonds did not exceed 2.41, which was slightly more than $14 \%$ of the maximum distance. In a similar grouping for 2012, the maximum distance within the cluster totaled a little more than in that 2004, because it was less than 2.44. This was, however, a smaller percentage of the maximum distance amounting to $12.2 \%$. As a result of this, the grouping obtained was at the same time smaller by one number of clusters. Despite the increase in the maximum distance among the clusters in 2012, some countries "drew nearer to each other", so the eight groups could be extracted (Klonowska-Matynia \& Sasin, 2015).

In 2014, by cutting off the branches of the tree at a distance of bonds equal to 8.64, two groups of countries were obtained and the distinction between the core countries (countries of the old EU) and the periphery (countries adopted after 2004 together with the countries of southern Europe) is clearly visible here. A similar picture was obtained with the rest in 2004 and 2012, but that was cutting off the branches at 9.32 and 9.8 respectively. At a distance equal to five, the effects of the grouping in 2014 allow you to distinguish four groups of countries. The relatively greatest number of bonds-10, can be observed at the level of binding of 2.41 (see Figure 3). 


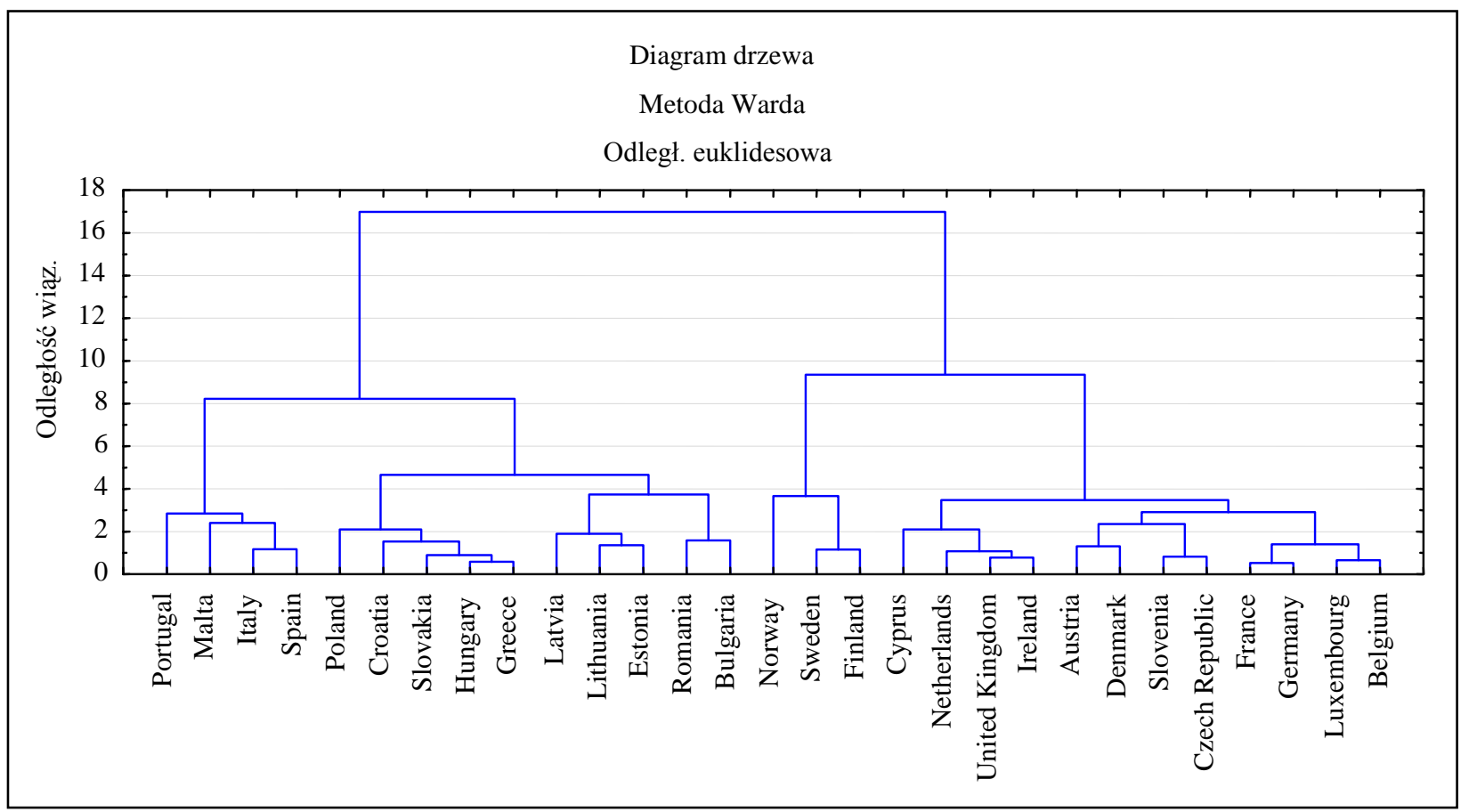

(a) 2004

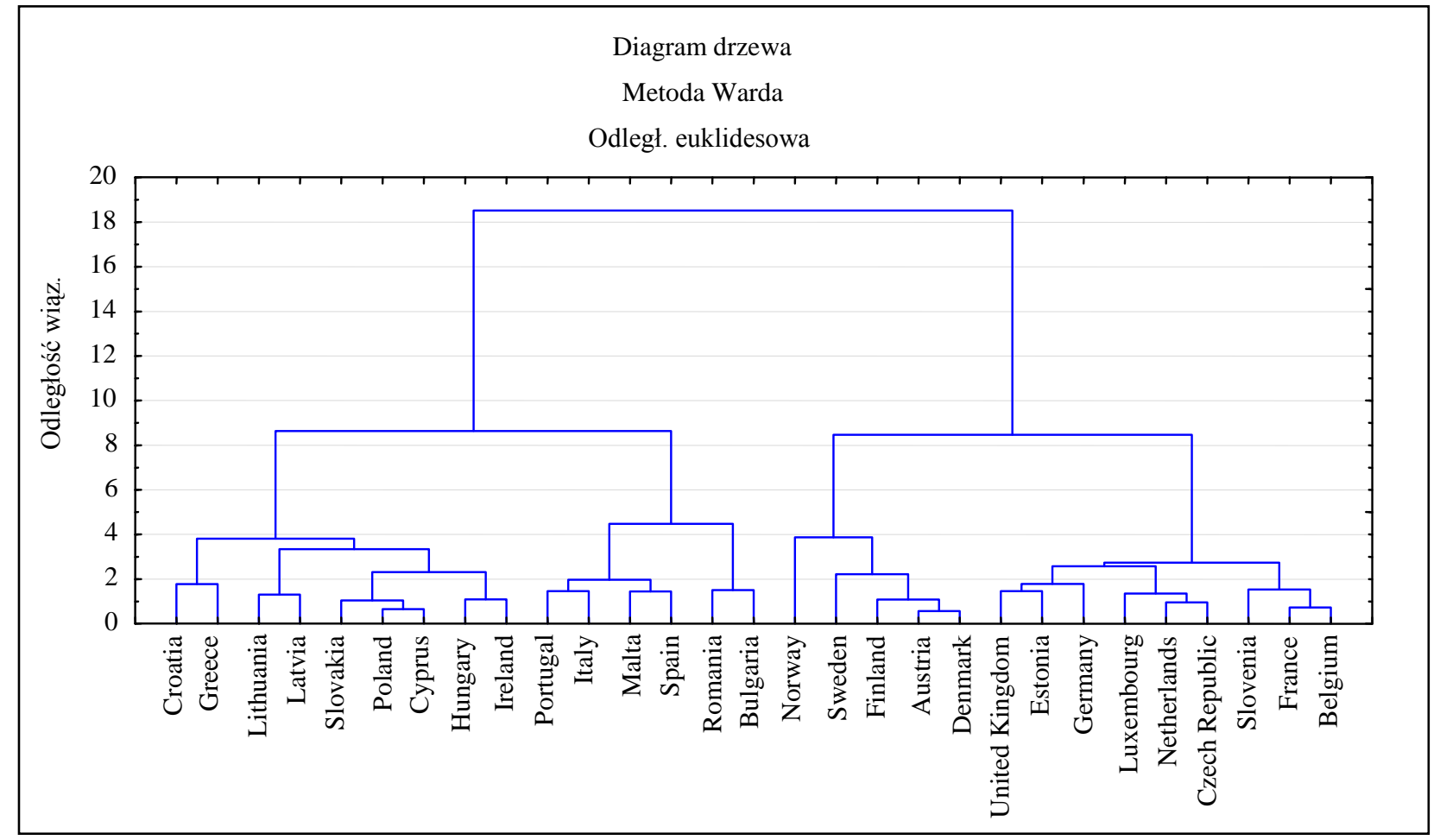

(b) 2014

Figure 3. The effects of grouping countries by Ward 2004 and 2014. Source: Own elaboration.

Mean levels of the traits studied were also presented in the figure, but in the interests of clarity and to illustrate the relationship of the average levels of the variables tested in separate groups, mean values of standardized variables were used. 
Table 5

Classification of Countries 2004 and 2014

\begin{tabular}{llll}
\hline Group & Countries 2004 & Group & Countries 2014 \\
\hline 1 & Portugal & 1 & Croatia and Greece \\
2 & Malta, Italy, and Spain & 2 & Latvia and Lithuania \\
3 & Poland, Croatia, Slovakia, Hungary, and Greece & 3 & Poland, Slovakia, Cyprus, Hungary, and Island \\
4 & Latvia, Lithuania, Estonia, Romania, and Bulgaria & 4 & Portugal, Malta, Italy, and Spain \\
5 & Norway & 5 & Romania and Bulgaria \\
6 & Sweden and Finland & 6 & Norway \\
7 & Cyprus, Netherlands, United Kingdom, and Ireland & 7 & Sweden, Finland, Austria, and Denmark \\
8 & Austria, Denmark, Slovenia, and Czech Republic & 8 & United Kingdom, Germany, and Estonia \\
9 & France, Germany, Luxembourg, and Belgium & 9 & Luxembourg, Czech Republic, and Netherlands \\
& & 10 & Slovenia, France, and Belgium \\
\hline
\end{tabular}

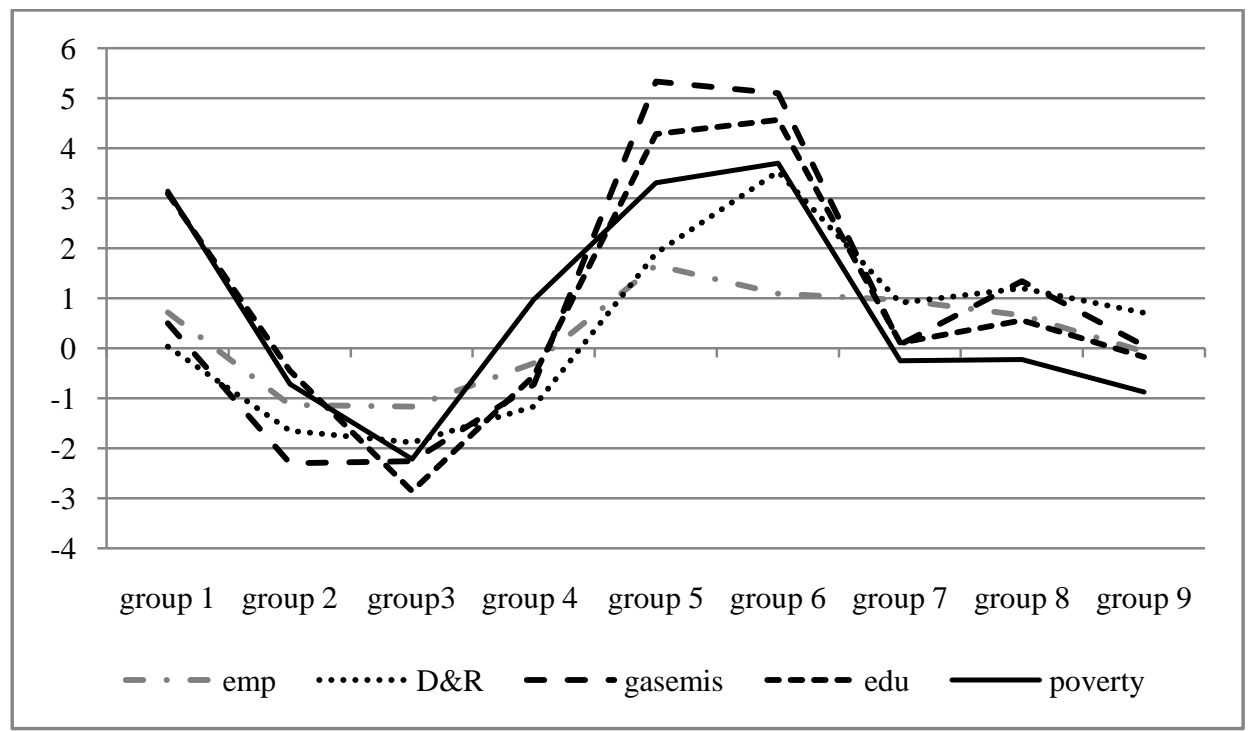

(a) 2004

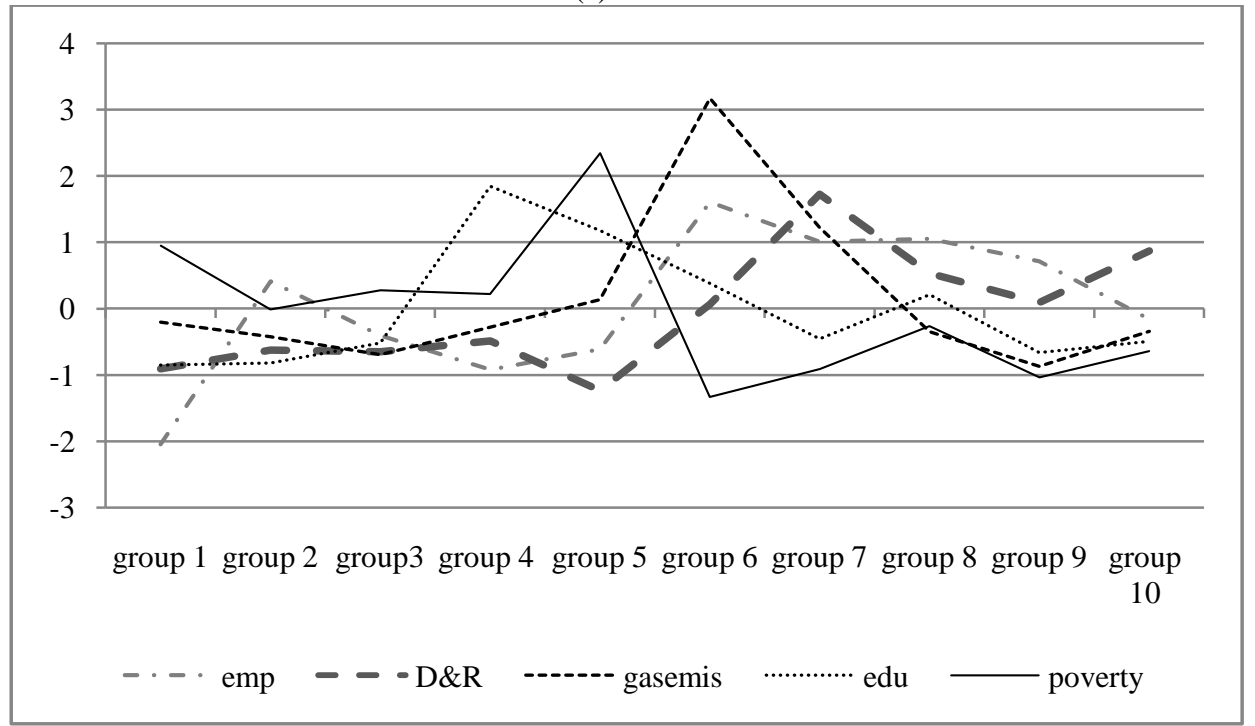

(b) 2014

Figure 4. The average values of each indicator for groups of countries 2004 and 2014. Source: Own elaboration. 
The effects of the grouping for 2014 are slightly different from 2004, both as to the size of the particular groups and the classification of the countries in each group (Table 5). Generally 10 groups are obtained. These are separated into two distinctive concentrations, better than the average level of employment and share of renewable energy (group 6 and 7). Norway (group 6) constituting a single unit collection stood out among all the analyzed groups for having the highest share of renewable energy, the lowest share of people at risk of poverty, high employment, and a slightly higher than average share of people leaving early education. Group 7 (Sweden, Finland, Austria, and Denmark) is a group with a relatively favorable situation with respect to other groups. In relation to group 6, this group has a better situation in the field of education and decidedly higher expenditures in the field of research and development. Just like in the grouping in 2004, the situation in the countries of these groups was the most advantageous. The worst situation in terms of the traits studied appeared in the second (Croatia and Greece) and fifth (Romania and Bulgaria) groups. Aggravating the situation in particular, are poverty, low employment, and a lack of investment in R\&D.

An interesting conclusion must be based on the analysis bonds at a distance of 8.64. On this basis, two clearly differentiated groups of countries were selected in terms of the level of sustainability for both points in time. A characteristic division into two clusters of countries can be observed, "the poorer and the richer". In the group of richer countries are the 14 countries (apart from the Czech Republic, Estonia, Slovenia, and Norway) that form the core of the EU, obtaining a GDP percentage above the EU average. The second concentration, amounting to 15 countries, is the decidedly poorer European countries, mainly including the new members of the EU and four countries (Greece, Italy, Spain, and Portugal) of southern Europe, who have been in the EU since the 1980s (and Italy since 1952), but which have been struggling with serious economic problems (mainly mounting debt and the lack of sustainability in public finances) in recent years. This clearly outlines the division of countries here based on the historical-political-geographical criterion for the countries of the former Eastern bloc countries (core and periphery), and the division between the rich North and the poor South, which also has its explanation in economic theories. The described effect was noticeable at both time points (in 2004 and 2014 and also in 2012), comparing to results of researches described in Klonowska-Matynia and Sasin's works (2015).

In an attempt to verify the strength of the factors determining the level of the synthetic indicator of growth in 2014, a regression equation was used. Two factors of comparable strength determined the index level of development. First of all employment, a feature associated with the activity in the labor market, at $66 \%$ explained the human development index level and the level of expenditure on research and development $\left(R^{2}=67 \%\right)$ were also selected. The number of people at risk of poverty at $62 \%$ explained the level of the human development index. Other features namely the number of early school leavers and the environmental component seem to have a weaker explanatory power $\left(R^{2}=26\right.$ respectively and $\left.R^{2}=30 \%\right){ }^{4}$ The results indicate a slightly weaker strength shown by the key features than for 2012 and 2004, comparing to results of researches described in Klonowska-Matynia and Sasin's works (2015). With each subsequent period, an increase in the explanatory power of the social dimension of the obtained level of socio-economic development was observed.

\section{Conclusions}

The hierarchy and classification of European countries in terms of a socio-economic development

\footnotetext{
${ }^{4}$ The attempt to assess the determinants of human development index in 2004 shows similar accuracy, with a slightly lower explanatory power of the studied traits.
} 
indicator reached were carried out using several applications. Conclusions are drawn as follows:

(1) Based on three pillars (social, economic, and environmental), it is concluded that the development gap among European countries has reduced, though the average level of development is slightly increasing in Europe. A study conducted in the 10-year interval, in the context of these results, confirms that the process of reducing disparities and development is a slow and long-term process. At present, strong spatial differentiation of European countries, in terms of development, continues despite the undisputed dynamic and positive changes occurring in the less developed European countries. However, the catching-up process of development is highly diversified.

(2) The performed analyses allow three groups of countries (both in the resulting hierarchy and the method of grouping) to be distinguished. Nordic countries and the countries of the so-called EU core are characterized by the highest standard of living and the best economic situation. The changes taking place in these countries, however, are characterized by a relatively low growth rate, which is a characteristic of mature economies. The exception is the United Kingdom which continues with an above-average relative level of human development index, while the pace of its growth is above average. The second group of countries is the countries of the former "Eastern bloc" who joined the EU during the enlargement in 2004. They are currently in the process of catching up with their richer neighbors. Especially dynamic are the changes taking place in three of them: Poland, Bulgaria, and Malta. They are characterized by relatively high dynamics of changes, mainly in the social sphere. These changes should be assessed positively. The third group is countries which have been in the EU over the years, the countries of southern Europe (Spain, Greece, Italy, and Portugal) and Malta. The results of the statistical analysis indicate that the compositional characteristics of the economic component (mainly employment and investment in R\&D) determine the level of the strongest indicator of growth. It may, therefore, be presumed that due to a decrease in labor market activity during the period, which is a result of the economic crisis, these countries' developmental changes were poor or were not noticeable. Despite the relatively low level of human development index, high dynamic changes in the relative level of development took place in Malta and Spain, which positively distinguish these countries from the group analyzed.

(3) It should be emphasized that the emerging groups are internally heterogeneous, which means that they exhibit differences in accepted characteristics in environment-economy-society for testing. They are also characterized by varying paces of change in the period analyzed (2004 and 2014) and different levels of socio-economic development of the synthetic indicator.

(4) By analyzing changes in the level of development of European countries at two time points (2004 and 2014), the catching-up process of development by the countries of Central and Eastern Europe, among which the leader is Poland, can be visibly observed.

(5) Among the newly admitted (after 2004) countries, the situation is most favorable in the Czech Republic, Estonia, and Slovenia, which are at a higher level of development than Poland and other countries of the former Eastern bloc. Even in countries with the lowest level of development, i.e., Bulgaria and Malta, very dynamic positive changes, primarily in the social sphere also occurred, but this does not change the fact that the level of development in these countries compared to other European countries is relatively low.

(6) The attempt to identify the main features (from the areas of environment, economy, and society) which determine the synthetic indicator's crucial level of development does not allow to identify any one particular determinant of the studied traits as critical. If as many as three of the five traits under examination (two of them economic pillars and one of the society pillars) are comparatively strong, this explains the value of the index. 
They are indisputably linked to the factors of knowledge and human capital. As the environmental and educational component has proven to be of less significance, the value of the model's interpretation should be considered unsatisfactory.

\section{References}

Anselin, L., Varga, A., \& Acs, Z. (1997). Local geographic spillovers between university research and high technology innovations. Journal of Urban Economics, 42(3), 422-448.

Antonelli, C. (1999). The microdynamics of technological change. London: Routledge.

Becker, G. S. (1964). Human capital. New York: Columbia University Press.

Bell, D. (1973). The coming of post-industrial society: A venture in social forecasting. New York: Basic Books.

Bercovitz, J., \& Feldman, M. (2006). Entrepreneurial universities and technology transfer: A conceptual framework for understanding knowledge-based economic development. The Journal of Technology Transfer, 31(1), 175-188.

Coyle, D., \& Quah, D. (2002). Getting the measure of the new economy. London: The Work Foundation.

European Commission. (2010). Europe 2020. A strategy for smart, sustainable and inclusive growth. Retrieved from http://www.mg.gov.pl

European Commission. (2011). Efficient Europe resources-Flagship initiative strategy "Europe 2020". Retrieved from http://www.eur-lex.europa.eu

Fageberg, J. (1994). Technology and international differences in growth rates. Journal of Economic Literature, 32(3), 1147-1175.

Foray, D., \& Lundvall, B. A. (1996). The knowledge based economy: From the economics of knowledge to the learning economy (in OECD documents: Employment and growth in the knowledge-based).

Giovannini, E., \& Linster, M. (2005). Measuring sustainable development. Achievements and challenges. Retrieved from https://www.regjeringen.no/globalassets/upload/FIN/berekraftig/Giovannini_Linster.pdf

Jones, G., \& Schneider, W. J. (2006). Intelligence, human capital, and economic growth: A Bayesian averaging of classical estimates (Bace) approach. Journal of Economic Growth, 11(1), 71-93.

Jones, L., \& Manuelli, R. (1990). A convex model of equilibrium growth: Theory and policy implications. Journal of Political Economy, 98, 1008-1038.

Klonowska-Matynia, M. (2012). The level of education vs. human capital employment. Annals of the Association of Agricultural and Agribusiness Economists, 14(6), 114-118.

Klonowska-Matynia, M. (2013). Economics of European integration. Towards the knowledge economy. Selected problems. Koszalin: Publishing College Koszalin University of Technology.

Klonowska-Matynia, M., \& Sasin, M. (2015). The sustainable development of EU countries in the context of Europe 2020 strategy. Annual Set The Environment Protection, 17, 771-791.

Lucas, R. (1988). On the mechanics of economic development. Journal of Monetary Economics, 22(1), 3-42.

Mankiw, N. G., Romer, D., \& Weil, D. N. (1992). A contribution to the empirics of economic growth. Quarterly Journal of Economics, 107, 407-437.

Mincer, J. (1962). On-the-job training: Costs, returns and some implications. Journal of Political Economy, 70(5), $50-79$.

Nonaka, I., \& Takeuchi, H. (1995). The knowledge creating company. Oxford: Oxford University Press.

Nowak, E. (1990). Taxonomic methods in the classification of socio-economic objects. Warsaw: PWE.

Rodrigues, M. J. (2004). European policies for a knowledge economy. Cheltenham: Edward Elgar.

Rodrigues, M. J. (2003). Introduction: For a European strategy at the turn of the century. In M. J. Rodrigues (Ed.), The new knowledge economy in Europe: A strategy for international competitiveness and social cohesion. Cheltenham: Edward Elgar.

Romer, P. M. (1986). Increasing returns and long-run growth. Journal of Political Economy, 94, 1002-1037.

Romer, P. M. (1990). Human capital and growth: Theory and evidence. Carnegie-Rochester Conference Series on Public Policy, 32(1), 251-286.

Schultz, T. W. (1980). Investment in entrepreneurial ability. Scandinavian Journal of Economics, 82(4), 437-448.

Stiglitz, J. (1999). Knowledge in the modern economy. Proceedings from Economics of the Knowledge Driven Economy Conference.

Toffler, A. (1997). The third wave. Warszawa: PIW. 